\title{
Comparison between genetic parameters of cheese yield and nutrient recovery or whey loss traits measured from individual model cheese-making methods or predicted from unprocessed bovine milk samples using Fourier-transform infrared spectroscopy
}

\author{
G. Bittante, A. Ferragina, C. Cipolat-Gotet, and A. Cecchinato ${ }^{1}$ \\ Department of Agronomy, Food, Natural Resources, Animals and Environment (DAFNAE), University of Padova, Viale dell'Università 16, \\ 35020 Legnaro, Italy
}

\begin{abstract}
Cheese yield is an important technological trait in the dairy industry. The aim of this study was to infer the genetic parameters of some cheese yield-related traits predicted using Fourier-transform infrared (FTIR) spectral analysis and compare the results with those obtained using an individual model cheese-producing procedure. A total of 1,264 model cheeses were produced using $1,500-\mathrm{mL}$ milk samples collected from individual Brown Swiss cows, and individual measurements were taken for 10 traits: 3 cheese yield traits (fresh curd, curd total solids, and curd water as a percent of the weight of the processed milk), 4 milk nutrient recovery traits (fat, protein, total solids, and energy of the curd as a percent of the same nutrient in the processed milk), and 3 daily cheese production traits per cow (fresh curd, total solids, and water weight of the curd). Each unprocessed milk sample was analyzed using a MilkoScan FT6000 (Foss, Hillerød, Denmark) over the spectral range, from 5,000 to 900 wavenumber $\times \mathrm{cm}^{-1}$. The FTIR spectrum-based prediction models for the previously mentioned traits were developed using modified partial least-square regression. Cross-validation of the whole data set yielded coefficients of determination between the predicted and measured values in crossvalidation of 0.65 to 0.95 for all traits, except for the recovery of fat (0.41). A 3-fold external validation was also used, in which the available data were partitioned into 2 subsets: a training set (one-third of the herds) and a testing set (two-thirds). The training set was used to develop calibration equations, whereas the testing subsets were used for external validation of the calibration equations and to estimate the heritabilities
\end{abstract}

Received April 30, 2014.

Accepted June 27, 2014.

${ }^{1}$ Corresponding author: alessio.cecchinato@unipd.it and genetic correlations of the measured and FTIRpredicted phenotypes. The coefficients of determination between the predicted and measured values in crossvalidation results obtained from the training sets were very similar to those obtained from the whole data set, but the coefficient of determination of validation values for the external validation sets were much lower for all traits (0.30 to 0.73$)$, and particularly for fat recovery (0.05 to 0.18), for the training sets compared with the full data set. For each testing subset, the (co)variance components for the measured and FTIR-predicted phenotypes were estimated using bivariate Bayesian analyses and linear models. The intraherd heritabilities for the predicted traits obtained from our internal cross-validation using the whole data set ranged from 0.085 for daily yield of curd solids to 0.576 for protein recovery, and were similar to those obtained from the measured traits (0.079 to 0.586 , respectively). The heritabilities estimated from the testing data set used for external validation were more variable but similar (on average) to the corresponding values obtained from the whole data set. Moreover, the genetic correlations between the predicted and measured traits were high in general (0.791 to 0.996), and they were always higher than the corresponding phenotypic correlations $(0.383$ to 0.995 ), especially for the external validation subset. In conclusion, we herein report that application of the cross-validation technique to the whole data set tended to overestimate the predictive ability of FTIR spectra, give more precise phenotypic predictions than the calibrations obtained using smaller data sets, and yield genetic correlations similar to those obtained from the measured traits. Collectively, our findings indicate that FTIR predictions have the potential to be used as indicator traits for the rapid and inexpensive selection of dairy populations for improvement of cheese yield, milk nutrient recovery in curd, and daily cheese production per cow.

Key words: genetic parameter, mid-infrared spectroscopy, cheese yield, whey loss, cross-validation 


\section{INTRODUCTION}

Several traits are very important for the dairy industry in relation to cheese-making processes, including the cheese yield and the proportion of various milk nutrients that are retained in the curd or lost in whey. Cipolat-Gotet et al. (2013) used a model cheese-making procedure on a large number of individual samples and found that the cheese yield and nutrient recovery or whey loss traits were heavily affected by the herd (and thus by environmental, nutritional, and management factors) and individual factors (e.g., parity, stage of lactation, and milk yield of cows). Even after accounting for these factors, however, a large proportion of the individual variability remained unexplained. Using the same large data set, Bittante et al. (2013) found that all of these traits were characterized by heritability coefficients similar to or higher than those of milk yield and the fat and protein contents of the milk. The genetic correlations between cheese yields and milk composition were found to be high, but far from unity, and those between curd recovery or whey loss traits and milk composition were rather low. The authors concluded that the inclusion of milk fat and protein contents in the selection indices is an effective tool when seeking to indirectly select for cheese yield, but it cannot explain all of the genetic variability in these traits. Although such traits were much less useful for the indirect selection of nutrient recoveries in curd or losses in whey, the authors concluded that selection for these traits could contribute to increasing profitability in the milk production or cheese-making chain.

Unfortunately, although the evaluation of cheese yield traits through model cheese production is repeatable, it is also expensive and very time-consuming. Thus, these traits cannot be routinely measured on a large scale for direct genetic improvement at the population level. Similar problems in assessing other traits have been addressed by using predictions obtained from specific calibrations based on Fourier transform infrared (FTIR) spectrometry. The transmittance or absorbance of milk samples at individual wavelengths in the medium infrared and near infrared (NIR) regions of the electromagnetic spectrum are demonstrably associated with many chemical bonds (Barbano and Lynch, 2006; Brandt et al., 2010; Karoui et al., 2010) and are often heritable (Soyeurt et al., 2010; Bittante and Cecchinato, 2013; Dagnachew et al., 2013). The FTIR spectrometer-based predictions of milk fat, protein, casein, and lactose contents (Hewavitharana and van Brakel, 1997; Etzion et al., 2004; Kaylegian et al., 2006) have become routine in laboratories that analyze milk samples for the milk recording of dairy cows and other ruminants (ICAR, 2012). The FTIR spectroscopy has also been proposed as a means to predict other interesting milk traits for which genetic parameters have been estimated, including FA profiles (Soyeurt et al., 2007b; Rutten et al., 2010; Bastin et al., 2011), detailed protein compositions (Arnould et al., 2009), milk coagulation traits (Bittante et al., 2012), and mineral profiles (Soyeurt et al., 2009). However, only one previous report compared the genetic parameters of measured and predicted traits (Cecchinato et al., 2009). Moreover, those authors emphasized the importance of estimating the genetic correlations between measured and predicted traits to correctly evaluate the effectiveness of using predicted traits for the indirect selection of desired traits.

Ferragina et al. (2013) recently reported FTIR calibrations for the major traits related to cheese yield and nutrient recovery in curd or loss in whey. Similar to the majority of studies on other milk traits, these authors calibrated the whole data set using the technique of cross-validation. In contrast, the study of Cecchinato et al. (2009) used a small subset for calibration and the rest of the data set for their validation and genetic analysis. The aims of the present study were (1) to compare the use of internal cross-validation versus external validation techniques when using FTIR spectrum-based calibrations to predict several traits related to cheese yield and nutrient recovery in milk or losses in whey; (2) to estimate the genetic parameters of the predicted cheese yield and nutrient recovery traits; (3) to compare these genetic parameters with those estimated for the corresponding traits measured following individual model cheese fabrication; (4) to estimate the genetic correlations between corresponding predicted and measured traits and consider using the former as indicator traits for the indirect selection of dairy populations; and (5) to compare the use of internal crossvalidation versus external validation techniques on the genetic parameters of predicted traits and the genetic correlations between the predicted and measured traits.

\section{MATERIALS AND METHODS}

\section{Field Data}

The present study is part of the Cowplus Project. The production environment, which was previously described in Sturaro et al. (2013), represented the variety of dairy systems in the Alps, from small traditional farms to large modern systems. A total of 1,264 Brown Swiss cows from 85 herds located in Trento Province (Italy) were sampled once during evening milking (15 cows were sampled per herd, with a few exceptions, and 1 herd was sampled per day). The cows represented different parities (1 to 5), DIM (5 to 449), and production levels $\left(24.3 \pm 7.9 \mathrm{~kg} \times \mathrm{d}^{-1}\right)$. The sampling procedure 
was described in detail by Cipolat-Gotet et al. (2012) and Cecchinato et al. (2013). Two milk subsamples per cow were collected and immediately refrigerated at $4^{\circ} \mathrm{C}$ without any preservative. One subsample $(50 \mathrm{~mL})$ was transported to the Milk Quality Laboratory of the Breeders' Federation of Trento Province (Trento, Italy) for composition analysis. The other subsample $(2,000$ $\mathrm{mL}$ ) was transferred to the Cheese-Making Laboratory of the Department of Agronomy, Food, Natural Resources, Animals and Environment of the University of Padova (Legnaro, Italy) for model cheese fabrication. All samples were processed for analyses and model cheese fabrication within $20 \mathrm{~h}$ from collection. Data on the cows and herds were provided by the Superbrown Consortium of Bolzano and Trento (Italy), and pedigree information was supplied by the Italian Brown Swiss Cattle Breeders Association (Verona, Italy). We included cows with phenotypic records available for the investigated traits and all known ancestors. Each sampled cow had at least 4 generations of known ancestors, and the pedigree file included 8,845 animals. A total of 1,326 sires were used; of them, 264 had progeny with records in the data set used in the present study, with each sire having between 2 and 80 daughters.

\section{Model Cheese-Making Procedure}

Individual milk samples were analyzed for their fat, protein, and casein percentages using a MilkoScan FT6000 (Foss, Hillerød, Denmark). Somatic cell counts were obtained with a Fossomatic FC counter (Foss) and converted to SCS by means of logarithmic transformation (Ali and Shook, 1980). The cheese-making procedure was previously described in detail (Cipolat-Gotet et al., 2013). Briefly, 1,500 mL of milk was heated to $35^{\circ} \mathrm{C}$ in a stainless steel microvat, supplemented with thermophilic starter culture, and mixed with rennet. The resulting curd from each vat was cut, drained, shaped in wheels, pressed, salted, and weighed. The whey collected from each vat was also weighed, sampled, and analyzed.

\section{Trait Definitions}

All of the traits were measured based on the weights (W;g) and chemical compositions of milk and whey, as detailed by Cipolat-Gotet et al. (2013). The measured traits were

- cheese yield (\%) as W of curd $\times 100 / \mathrm{W}$ of milk;

- total solid (TS) cheese yield $\left(\mathbf{C Y}_{\text {Solids }}, \%\right)$ as (W of milk TS $-\mathrm{W}$ of whey TS) $\times 100 / \mathrm{W}$ of milk;

- water cheese yield (CY $\left.\mathbf{C Y}_{\text {WATER }}, \%\right)$ as (W of milk water $-\mathrm{W}$ of whey water $) \times 100 / \mathrm{W}$ of milk;
- fat (F) recovery $\left(\mathbf{R E C}_{\mathrm{FAT}}, \%\right)$ as (W of milk F W of whey F) $\times 100 / W$ of milk F;

- protein (P) recovery (REC $\mathbf{P R o t e i n}_{\text {, }} \%$ ) as (W of milk $\mathrm{P}-\mathrm{W}$ of whey $\mathrm{P}) \times 100 / \mathrm{W}$ of milk $\mathrm{P}$;

- TS recovery (\%) as (W of milk TS - W of whey TS $\times 100 / \mathrm{W}$ of milk TS; and

- energy recovery (\%) as (milk energy - whey energy) $\times 100 /$ milk energy.

\section{FTIR Spectral Acquisition and Calibration}

Each individual milk sample was analyzed using a MilkoScan FT6000 (Foss) over the spectral range from 5,000 to 900 wavenumber $\times \mathrm{cm}^{-1}$; the spectra were stored as absorbance (A) using the transformation $\mathrm{A}=$ $\log (1 / \mathrm{T})$, where $\mathrm{T}$ is the transmittance. Two spectral acquisitions were carried out for each sample, and the results were averaged before data analysis. Calibration models were developed using the WinISI II software (Infrasoft International LLC, State College, PA) and carried out using modified partial least-square regression as the chemometric algorithm, as described in detail by Ferragina et al. (2013).

\section{Predictive Ability}

A 3-fold cross-validation or external validation procedure was used to assess the ability of the calibration equations to predict individual cheese yield-related phenotypes [i.e., cheese yields $(\mathbf{C Y})$ and recoveries (REC)] and assess the magnitude of the genetic correlation between CY and REC measures and their FTIR spectrum-based predictions. Similar cross-validation procedures have been used successfully in animal breeding (Caraviello et al., 2004). This cross-validation is not as computationally demanding as a leave-one-out can be, and makes complete use of the data (versus having 1 training subset and 1 testing subset). Basically, the entire data set was randomly (by herd) partitioned into 3 disjoint subsets, each containing approximately one-third of the records ( $\sim 28$ herds per subset). For the internal cross-validation procedure, 1 subset was used for fitting and prediction (training set) and the remaining 2 subsets (external validation) were used to test predictive ability (testing set). The calibration equations obtained from the training set were used to predict the CY and REC traits from the FTIR spectra of the testing set. The predicted and measured traits of the testing set were both used to estimate their heritabilities and genetic correlations, which were considered the final external genetic validation of the FTIR calibration procedure. In this 3 -fold cross-validation, the observations included in the testing set were completely independent from those used to build the calibration 
equations. In addition, a standard full cross validation was performed by applying the calibration equations obtained by Ferragina et al. (2013) to the same data set. In this case, the full data set (milk samples from 1,264 cows) was used as the testing set for estimating the heritabilities and genetic correlations of the measured and predicted CY and REC; this was the same data set as the training set, and thus included observations that were not independent from those used to build the calibration equations (internal cross-validation). Throughout the current paper, the first 3-fold cross-validation is referred to as the external validation, whereas that obtained with using the equations obtained by Ferragina et al. (2013) is called the internal validation.

\section{Genetic Analysis}

For each testing set, the (co)variance components for the CY and REC measures and their FTIR spectrumbased predictions were estimated through bivariate analyses and linear models. The general model assumed for the former traits was

$$
y_{i j k l}=\mathrm{DIM}_{i}+\text { Parity }_{j}+h_{k}+a_{l}+\varepsilon_{i j k l},
$$

where $y_{i j k l}$ is the phenotypic record for the analyzed trait; $\mathrm{DIM}_{i}$ is the effect of the $i$ th class of DIM $(i=1$ to 10; $30 \mathrm{~d}$ for each class with class 1 being $<30 \mathrm{~d}$ and class 10 being $>300 \mathrm{~d}$ ); Parity ${ }_{j}$ is the effect of the $j$ th parity of the cow ( $j=1$ to 5 or more); $h_{k}$ is the effect of the $k$ th herd ( $k=1$ to 28 for the first subset, 1 to 28 for the second subset, 1 to 29 for the third subset, and 1 to 85 for the entire data set); $a_{l}$ is the infinitesimal genetic effect of individual $l$; and $\varepsilon_{i j k l}$ is the residual of the model.

\section{Bayesian Inference}

Variance (and covariance) components and related parameters were estimated using a Bayesian approach and Markov-chain Monte Carlo methods (Sorensen and Gianola, 2002). All traits (measures and predictions) were taken as continuous variables, and their values were assumed to be sampled from the following multivariate normal distribution:

$\left[\begin{array}{l}\mathrm{y}_{1} \\ \mathrm{y}_{2}\end{array}\right] \mid \mathbf{b}_{1}, \mathbf{b}_{2}, \mathbf{h}_{1}, \mathbf{h}_{2}, \mathbf{a}_{1}, \mathbf{a}_{2}, \mathbf{R} \sim \mathbf{N}\left(\mathbf{X}\left[\begin{array}{l}\mathbf{b}_{1} \\ \mathbf{b}_{2}\end{array}\right]+\mathbf{Z}_{1}\left[\begin{array}{l}\mathbf{h}_{1} \\ \mathbf{h}_{2}\end{array}\right]+\mathbf{Z}_{2}\left[\begin{array}{l}\mathbf{a}_{1} \\ \mathbf{a}_{2}\end{array}\right], \mathbf{R}\right)$,

in which $\mathbf{b}_{1}$ and $\mathbf{b}_{2}$ are random vectors including the effects of DIM and parity; $\mathbf{a}_{1}$ and $\mathbf{a}_{2}$ are vectors of individual additive genetic effects; $\mathbf{h}_{1}$ and $\mathbf{h}_{2}$ are vectors of herd effects; $\mathbf{X}, \mathbf{Z}_{1}$, and $\mathbf{Z}_{2}$ are known incidence matrices; and $\mathbf{R}$ is the residual (co)variance matrix. Between traits, the additive, herd, and residual effects were assumed to be correlated. When we sorted records by individual and within-individual traits, the residual (co)variance matrix could be written as $\mathbf{R}_{0} \otimes \mathbf{I}_{\boldsymbol{n}}$, with $\mathbf{R}_{0}$ being the $2 \times 2$ residual (co)variance matrix between the traits analyzed, and $\mathbf{I}_{\mathrm{n}}$ being an identity matrix of the appropriate order. Bounded uniform priors were used to represent vague previous knowledge of the distributions of $\mathbf{b}_{1}$ and $\mathbf{b}_{2}$. Prior knowledge concerning the additive effect and herd effect was represented by assuming that they were normally distributed conditional on the associated (co)variance components, as

$$
\begin{gathered}
{\left[\begin{array}{l}
\mathbf{a}_{1} \\
\mathbf{a}_{2}
\end{array}\right] \mid \mathbf{G} \sim \mathbf{N}(0, \mathbf{G}) \text { and }} \\
{\left[\begin{array}{l}
\mathbf{h}_{1} \\
\mathbf{h}_{2}
\end{array}\right] \mid \mathbf{H} \sim \mathbf{N}(0, \mathbf{H}),}
\end{gathered}
$$

where 0 is a vector of zeros; $\mathbf{G}$ is the genetic (co)variance matrix; and $\mathbf{H}$ is the (co)variance matrix of herd effects. When we sorted the data by individual (as described above), we could write matrices $\mathbf{G}$ and $\mathbf{H}$ as $\mathbf{G}_{0} \otimes \mathbf{A}$ and $\mathbf{H}_{0} \otimes \mathbf{I}_{\boldsymbol{s}}$, respectively, where $\mathbf{G}_{0}$ and $\mathbf{H}_{0}$ are the $2 \times 2$ genetic and herd (co)variance matrices, respectively; $\mathbf{A}$ is the known additive genetic relationship matrix; and $\mathbf{I}_{s}$ is the identity matrix of the same order as the number of levels of herd effects. Bounded uniform priors were used for the components of the (co) variance matrices $\mathbf{R}_{0}$ and $\mathbf{G}_{0}$ and $\mathbf{H}_{0}$.

Marginal posterior distributions of unknown parameters were estimated by performing numerical integration through the Gibbs sampler (Gelfand and Smith, 1990), as implemented in the TM program (http://snp. toulouse.inra.fr/ alegarra); this generated autocorrelated samples from the joint posterior distributions and, subsequently, from the marginal posterior distributions of all unknowns in the model. The lengths of the chain and burn-in period were assessed by visual inspection of trace plots, and by the diagnostic tests described by Geweke (1992) and Gelman and Rubin (1992). After a preliminary run, we decided to construct a single chain consisting of 850,000 iterations and discard the first 50,000 iterations as a very conservative burn-in. Subsequently, 1 in every 200 successive samples was retained to store draws that were more loosely correlated. Thus, 4,000 samples were used to determine the posterior distributions of the unknown parameters. The lower and upper bounds of the highest $95 \%$ probability density regions for the parameters of interest were obtained from the estimated marginal densities. The posterior median was used as the point for all param- 
eters. Autocorrelations between samples and estimates of the Monte Carlo Standard Error (Geyer, 1992) were calculated. The effective sample size was evaluated using the algorithm of Geyer (1992).

Across-herd heritability was computed as

$$
h_{\mathrm{AH}}^{2}=\frac{\sigma_{\mathrm{A}}^{2}}{\sigma_{\mathrm{A}}^{2}+\sigma_{\mathrm{H}}^{2}+\sigma_{\mathrm{E}}^{2}},
$$

where $\sigma_{\mathrm{A}}^{2}, \sigma_{\mathrm{H}}^{2}$, and $\sigma_{\mathrm{E}}^{2}$ are the additive genetic, herd, and residual variances, respectively.

Intraherd heritability was computed as

$$
h_{\mathrm{IH}}^{2}=\frac{\sigma_{\mathrm{A}}^{2}}{\sigma_{\mathrm{A}}^{2}+\sigma_{\mathrm{E}}^{2}},
$$

where $\sigma_{\mathrm{A}}^{2}, \sigma_{\mathrm{H}}^{2}$, and $\sigma_{\mathrm{E}}^{2}$ are the additive genetic, herd or test-date, and residual variances, respectively.

Additive genetic correlations were estimated as

$$
r_{\mathrm{A}}=\frac{\sigma_{A 1, A 2}}{\sigma_{A 1}+\sigma_{A 2}}
$$

where $\sigma_{A 1, A 2}$ is the additive genetic covariance between traits 1 and 2; and $\sigma_{A 1}$ and $\sigma_{A 2}$ are the additive genetic standard deviations for traits 1 and 2, respectively.

\section{RESULTS}

\section{Calibration, Prediction, and Validation of $C Y$ and $R E C$}

Table 1 presents the number of milk samples used to calibrate the FTIR spectrometer for predicting the CY and nutrient REC traits (training set). For all 7 predicted traits, the first 3 calibration rounds were carried out on 3 training sets (subsets A, B, and C) containing similar numbers of cows, which were obtained dividing all sampled farms into 3 groups. The 2 subsets not used for calibration were used for external validation of the predictions (testing set). The forth calibration round was carried out using the whole data set $(\mathrm{A}+\mathrm{B}+\mathrm{C})$; in this case, no external validation was possible, and an internal validation was conducted by cross-validation of the same data set. For each of the studied traits, the training and testing sets had all means and SD very similar to those of the whole data set $(\mathrm{A}+\mathrm{B}+\mathrm{C}$; Table $1)$.

As in all the rounds, the calibration process was carried out through a randomized cross-validation within the training set to compare the different rounds the standard errors of internal cross-validation and the coefficient of determination of cross-validation $(\mathbf{1}-\mathbf{V R}$, where $\mathrm{VR}=$ variance ratio), shown in Table 1 . The calibrations performed on the data subsets were characterized by some variability, but showed (on average) cross-validation parameters similar to those obtained from the whole data set for all traits, with the exception of $\mathrm{REC}_{\text {Protein }}$ in the curd. The $1-\mathrm{VR}$ values were high or very high (0.60 to 0.95 ) for all predictions, except for $\mathrm{REC}_{\mathrm{FAT}}$ (0.27 to 0.46). The external validation yielded standard errors for the predictions that were much higher than the corresponding values obtained during the cross-validations, and coefficients of determinations of validation $\left(R_{V}^{2}\right)$ that were much lower than those $(1-V R)$ of the internal validations for all analyzed traits (Table 1), with the highest value observed for $\mathrm{CY}_{\text {SOLIDS }}$ and the lowest for $\mathrm{REC}_{\mathrm{FAT}}$.

\section{Variance Components and Heritabilities for the Predicted and Measured Traits}

Table 2 reports the genetic parameters of the predicted and measured CY, expressed as a percent of the milk processed or as daily production per cow (according to the testing subset used), whereas Table 3 presents those of the nutrient recoveries. In general, the variabilities of the estimated variance components among the different testing subsets used for external validation $(\mathrm{B}+\mathrm{C}, \mathrm{A}+\mathrm{C}$, and $\mathrm{A}+\mathrm{B})$ were large. In fact, they were higher than those observed for the entire data set $(\mathrm{A}+\mathrm{B}+\mathrm{C})$ used for internal validation. On average, the variance components of the FTIR-predicted traits were lower than the corresponding variance components of the measured traits, with some exceptions (e.g., the herd variance components). As a consequence, the heritability estimates were also variable. Due to the high variability of the herd variance components, the variabilities of the across-herd heritability estimates tended to be higher than those of the intraherd heritability estimates (Tables 2 and 3). The majority of the heritability coefficients were in the range of 0.15 to 0.30 . However, a few exceptions were noted, such as the very high estimates obtained for $\mathrm{REC}_{\text {PRoteIn }}$ ( 0.230 to $0.661)$. The heritability estimates of the predicted traits were generally similar to those of the measured traits, tending higher or lower based on the importance of the relative variations (decreases) in the genetic, herd, and residual variance components. In the majority of cases, the heritabilities of the predicted traits were slightly higher than those of the measured traits because the genetic variance components of the predicted versus measured traits tended to be lower than the respective residual variance components (Tables 2 and 3 ). 
Table 1. Descriptive statistics of individual percentage cheese yield (CY; weight of fresh curd, curd solids, and curd water as percentage of weight of milk processed) and milk nutrient recovery (REC; protein, fat, solids, and energy of the curd as percentage of the protein, fat, solids, and energy of the milk processed) for each subset of data ${ }^{1}$



${ }^{1}$ Training set $=$ samples used to develop a calibration equation to predict individual phenotypes using mid-infrared $($ MIR) spectra; test set $=$ samples used to validate the calibration equation and to estimate heritabilities and the genetic correlation for measured phenotypes and their predictions obtained from MIR spectra and calibration equation.

${ }^{2} \mathrm{~A}, \mathrm{~B}$, and $\mathrm{C}=3$ training subsets randomly (by herd) partitioned; $\mathrm{A}+\mathrm{B}+\mathrm{C}=$ entire data set used both for training and testing (internal crossvalidation; $\mathrm{B}+\mathrm{C}=$ testing subset for the training subset $\mathrm{A} ; \mathrm{A}+\mathrm{C}=$ testing subset for the training subset $\mathrm{B} ; \mathrm{A}+\mathrm{B}=$ testing subset for the training subset $\mathrm{C}$.

${ }^{3} \mathrm{SEC}_{\mathrm{cv}}=$ standard error of cross-validation.

${ }^{4} 1-\mathrm{VR}=$ coefficient of determination of cross-validation, where $\mathrm{VR}=$ variance ratio.

${ }^{5} \mathrm{SEP}=$ standard error of prediction.

${ }^{6} R_{V}^{2}=$ coefficient of determination of validation.

\section{Genetic and Phenotypic Correlations Between Predicted and Measured Traits}

The genetic and phenotypic correlations between the measured and predicted CY traits, expressed as the percent of processed milk and daily production per cow, are shown in Table 4, whereas Table 5 presents the correlations between the predicted and measured nutrient REC. The phenotypic correlations were in the range of 0.459 to $0.962 \%$ for the CY traits, much higher $(0.787$ to 0.995$)$ for the daily production yields, and 0.383 to $0.905 \%$ for all of the REC traits. In general, the phenotypic correlations followed the same trait order observed for our external validation of the calibrations. The genetic correlations were less variable and always much higher than the phenotypic correlations, with values exceeding $0.846 \%$ for cheese yield and $\mathrm{CY}_{\text {SOLIDS }}$, 0.522 to $0.76 \%$ for $\mathrm{CY}_{\text {WATER }}, 0.887$ to $0.993 \%$ for daily production yield, and 0.791 to $0.981 \%$ for REC.

\section{DISCUSSION}

\section{Internal or External Validation for FTIR-Based Predictions of CY and REC}

The first aim of the current study was to compare cross-validation with external validation for FTIRbased predictions. In a previous study (Ferragina et al., 2013), the cross-validation of calibrations obtained on the whole data set yielded very high coefficients of determination all except for $\mathrm{CY}_{\text {WATER }}$ and $\mathrm{REC}_{\mathrm{FAT}}$. These results were confirmed in the present study. The FTIR 
Table 2. Posterior median (SD) for additive genetic $\left(\sigma_{\mathrm{A}}^{2}\right)$, herd $\left(\sigma_{\mathrm{H}}^{2}\right)$, and residual variance $\left(\sigma_{\mathrm{E}}^{2}\right)$ and across-herd $\left(h_{\mathrm{AH}}^{2}\right)$ and intraherd $\left(h_{\mathrm{IH}}^{2}\right)$ heritabilities for model cheese-making measures and predictions by mid-infrared spectroscopy (MIR) of percentage cheese yield (CY; weight of fresh curd, curd solids, and curd water as percentage of weight of milk processed) and daily production (dCY; curd, curd solids, and curd water produced per cow)

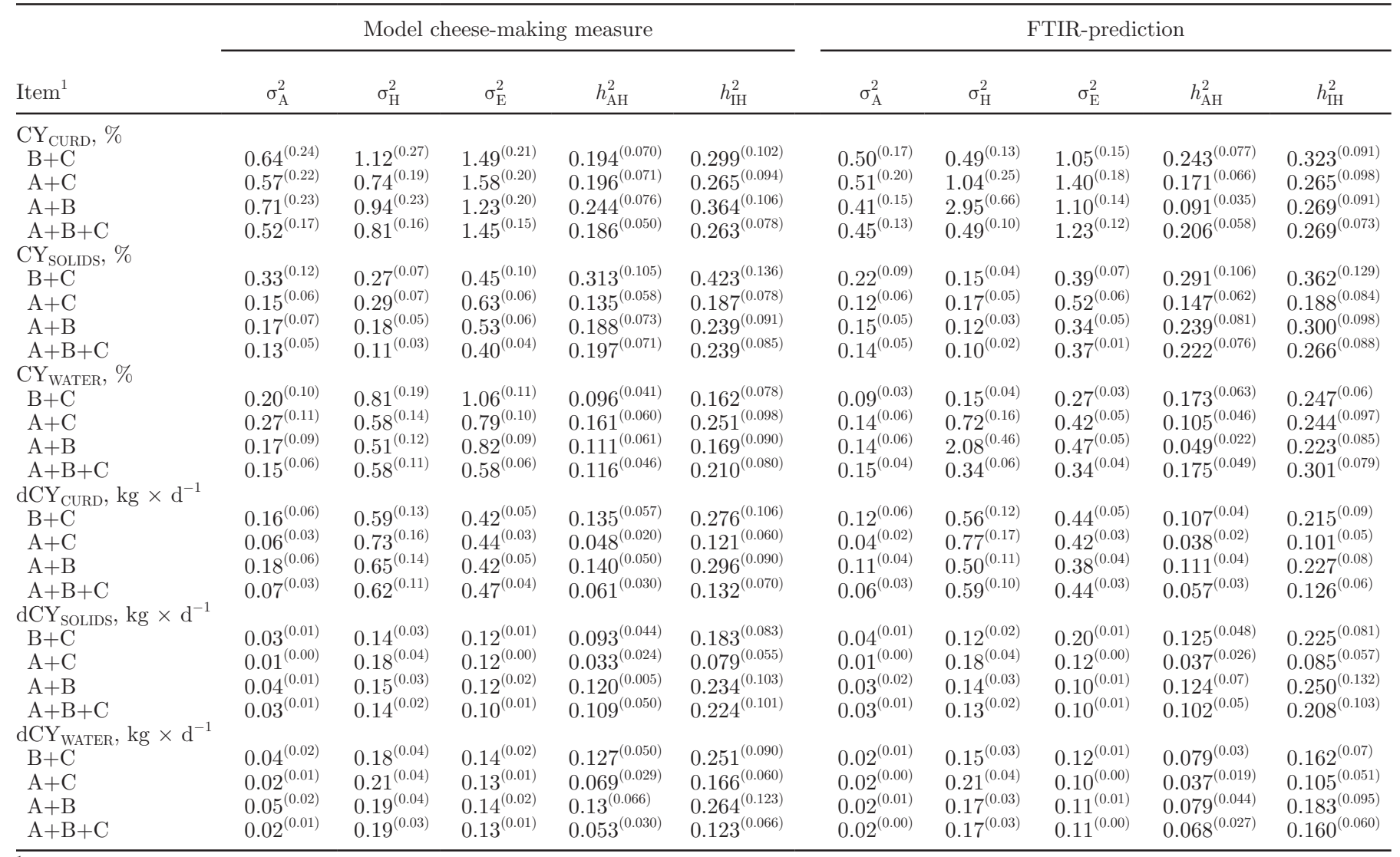

${ }^{1}$ Subsets A, B, and C are subsets of data used to validate the calibration equations and to estimate genetic parameters for measures of phenotypes and their predictions obtained from MIR spectra and calibration equations.

spectrometry may be used to predict many chemical components of food, taking advantage of the direct relationships between specific chemical bonds and the emission of electromagnetic radiations at specific wavelengths (Karoui et al., 2010; Bittante and Cecchinato, 2013). For example, the typical absorption peak for fat $\mathrm{A}$ is found at $\approx 1,740$ wavenumber $\times \mathrm{cm}^{-1}$. The transition between the mid- and long-wave infrared (MWIRLWIR region, called the fingerprint region and located between 1,582 and 930 wavenumber $\times \mathrm{cm}^{-1}$ ) contains the absorbance peaks characteristic of many chemical compounds (e.g., carbohydrates and organic acids). An example of this is lactose, which has an absorbance peak at $\approx 1,040$ wavenumber $\times \mathrm{cm}^{-1}$ (Lynch et al. 2006 ; Kaylegian et al. 2009). The coefficients of determination for the calibrations used to predict the fat, protein, and lactose contents of milk are close to unity, which is why International Committee for Animal Recording approved FTIR spectroscopy for the official measurement of milk samples collected for milk recording of lactating females (ICAR, 2012). However, CY and nutrient REC are technological traits rather than chemical parameters, which explains why their 1 - VR values are always lower than unity and may in fact be very low. It is not surprising that $\mathrm{CY}_{\text {SOLIDS }}$ had the highest $1-\mathrm{VR}$, given that it depends on the fat and protein contents of the milk processed. The observation that $\mathrm{CY}_{\text {WATER }}$ and $\mathrm{REC}_{\mathrm{FAT}}$ had the lowest $1-\mathrm{VR}$ reflects the finding that $\mathrm{CY}_{\text {WATER }}$ does not strongly depend on the chemical composition of the milk (even though water is its major component). In fact, the raw spectrum obtained from milk in the near- and mid-infrared wavelengths is very similar to that obtained for pure water (Kaylegian et al., 2009), and the transmittance of water can mask that due to the other components of milk. To avoid this problem, modern FTIR spectrometers express the milk spectrum as the ratio between the transmittance of milk and that of water for each individual wavelength (Bittante and Cecchinato, 2013). Moreover, the water retained in the curd does not appear to be strongly 
Table 3. Posterior median $(\mathrm{SD})$ for additive genetic $\left(\sigma_{\mathrm{A}}^{2}\right)$, herd $\left(\sigma_{\mathrm{H}}^{2}\right)$, and residual variance $\left(\sigma_{\mathrm{E}}^{2}\right)$ and across-herd $\left(h_{\mathrm{AH}}^{2}\right)$ and intraherd $\left(h_{\mathrm{IH}}^{2}\right)$ heritabilities for model cheese-making measures and predictions by mid-infrared spectroscopy (MIR) of milk nutrient recovery (REC; protein, fat, solids, and energy of the curd as percentage of the protein, fat, solids, and energy of the milk processed) and their predictions obtained from MIR spectra and calibration equations

\begin{tabular}{|c|c|c|c|c|c|c|c|c|c|c|}
\hline \multirow[b]{2}{*}{ Item $^{1}$} & \multicolumn{5}{|c|}{ Model cheese-making measure } & \multicolumn{5}{|c|}{ FTIR-prediction } \\
\hline & $\sigma_{\mathrm{A}}^{2}$ & $\sigma_{\mathrm{H}}^{2}$ & $\sigma_{\mathrm{E}}^{2}$ & $h_{\mathrm{AH}}^{2}$ & $h_{\mathrm{IH}}^{2}$ & $\sigma_{\mathrm{A}}^{2}$ & $\sigma_{\mathrm{H}}^{2}$ & $\sigma_{\mathrm{E}}^{2}$ & $h_{\mathrm{AH}}^{2}$ & $h_{\mathrm{IH}}^{2}$ \\
\hline \multicolumn{11}{|c|}{$\begin{array}{l}\mathrm{REC}_{\text {PROTEIN }}, \\
\%\end{array}$} \\
\hline $\mathrm{B}+\mathrm{C}$ & $1.71^{(0.58)}$ & $2.34^{(0.58)}$ & $3.31^{(0.51)}$ & $0.230^{(0.077)}$ & $0.338^{(0.108)}$ & $1.48^{(0.55)}$ & $1.18^{(0.30)}$ & $1.85^{(0.44)}$ & $0.323^{(0.109)}$ & $0.443^{(0.141)}$ \\
\hline $\mathrm{A}+\mathrm{C}$ & $2.48^{(0.74)}$ & $1.87^{(0.49)}$ & $2.93^{(0.61)}$ & $0.337^{(0.095)}$ & $0.458^{(0.120)}$ & $2.26^{(0.59)}$ & $1.78^{(0.45)}$ & $1.81^{(0.46)}$ & $0.383^{(0.093)}$ & $0.556^{(0.122)}$ \\
\hline $\mathrm{A}+\mathrm{B}$ & $2.94^{(0.66)}$ & $1.09^{(0.30)}$ & $1.51^{(0.50)}$ & $0.525^{(0.105)}$ & $0.660^{(0.120)}$ & $1.20^{(0.30)}$ & $1.60^{(0.39)}$ & $1.39^{(0.24)}$ & $0.282^{(0.070)}$ & $0.462^{(0.103)}$ \\
\hline $\mathrm{A}+\mathrm{C}$ & $2.48^{(1.08)}$ & $6.12^{(1.53)}$ & $13.34^{(1.19)}$ & $0.112^{(0.048)}$ & $0.156^{(0.065)}$ & $\begin{array}{l}2.48 \\
1.03^{(0.36)}\end{array}$ & $\begin{array}{l}3.12 \\
1.71^{(0.42)}\end{array}$ & $\begin{array}{l}2.40 \\
2.05^{(0.31)}\end{array}$ & $0.211^{(0.072)}$ & $0.501^{(0.105)}$ \\
\hline $\mathrm{A}+\mathrm{B}$ & $2.77^{(1.27)}$ & $3.24^{(0.90)}$ & $10.20^{(1.19)}$ & $0.169^{(0.070)}$ & $0.212^{(0.091)}$ & $0.37^{(0.20)}$ & $5.94^{(1.30)}$ & $1.62^{(0.19)}$ & $0.046^{(0.026)}$ & $0.185^{(0.093)}$ \\
\hline $\mathrm{A}+\mathrm{B}+\mathrm{C}$ & $1.80^{(0.57)}$ & $2.57^{(0.52)}$ & $4.81^{(0.51)}$ & $0.195^{(0.059)}$ & $0.271^{(0.080)}$ & $1.31^{(0.34)}$ & $1.31^{(0.26)}$ & $1.96^{(0.28)}$ & $0.283^{(0.069)}$ & $0.399^{(0.093)}$ \\
\hline \multicolumn{11}{|c|}{ REC $_{\text {ENERGY }}, \%$} \\
\hline $\mathrm{B}+\mathrm{C}$ & $3.04^{(1.20)}$ & $3.42^{(0.90)}$ & $7.65^{(1.08)}$ & $0.212^{(0.081)}$ & $0.281^{(0.104)}$ & $2.31^{(1.03)}$ & $1.45^{(0.43)}$ & $4.78^{(0.82)}$ & $0.268^{(0.104)}$ & $0.325^{(0.124)}$ \\
\hline $\mathrm{A}+\mathrm{C}$ & $1.80^{(0.94)}$ & $3.57^{(0.94)}$ & $9.54^{(0.95)}$ & $0.118^{(0.06)}$ & $0.157^{(0.079)}$ & $1.46^{(0.78)}$ & $2.98^{(0.75)}$ & $5.57^{(0.71)}$ & $0.144^{(0.074)}$ & $0.207^{(0.103)}$ \\
\hline $\mathrm{A}+\mathrm{C}$ & $1.94^{(0.96)}$ & $3.12^{(0.83)}$ & $8.23^{(0.91)}$ & $0.144^{(0.068)}$ & $0.189^{(0.087)}$ & $1.46^{(0.77)}$ & $2.37^{(0.63)}$ & $5.84^{(0.69)}$ & $0.148^{(0.074)}$ & $0.198^{(0.096)}$ \\
\hline$A+B$ & $2.72^{(1.00)}$ & $2.36^{(0.65)}$ & $6.27^{(0.89)}$ & $0.237^{(0.083)}$ & $0.302^{(0.102)}$ & $2.02^{(0.70)}$ & $2.52^{(0.65)}$ & $4.63^{(0.62)}$ & $0.218^{(0.073)}$ & $0.303^{(0.097)}$ \\
\hline $\mathrm{A}+\mathrm{B}+\mathrm{C}$ & $2.18^{(0.72)}$ & $1.84^{(0.41)}$ & $5.47^{(0.63)}$ & $0.228^{(0.071)}$ & $0.284^{(0.086)}$ & $1.89^{(0.66)}$ & $1.37^{(0.31)}$ & $4.60^{(0.56)}$ & $0.239^{(0.077)}$ & $0.290^{(0.091)}$ \\
\hline
\end{tabular}

${ }^{1}$ Subsets A, B, and C are subsets of data used to validate the calibration equations and to estimate genetic parameters for measures of phenotypes.

related to the water content of milk (Bittante et al., 2013), but rather to the processes of milk coagulation and syneresis and the hydration characteristics of the retained proteins and fats. Furthermore, REC $_{\mathrm{FAT}}$ depends primarily on the curd-firming process. Previous studies on milk samples from Holstein-Friesian (Dal Zotto et al., 2008) and Brown Swiss (Cecchinato et al., 2009) cows demonstrated that the prediction of milk coagulation properties by FTIR spectrometry is not very efficient.

With respect to cross-validation, a large body of literature exists describing different approaches. For example, when validating a curd syneresis sensor at the laboratory level, Mateo et al. (2009) found that external validation yielded (as expected) less favorable results then internal cross-validation; they further reported that the standard error of the predictions were more useful than $\mathrm{R}^{2}$ for comparisons with cross-validation, as the former were not strongly influenced by the number of data points or the range of reference values. When studying the possible utilization of FTIR predictions for the genetic improvement of milk coagulation traits, using a data set similar to that examined in the present study, Cecchinato et al. (2009), performed a pseudocross-validation. The variabilities of $\mathrm{R}^{2}$ in their calibrations (0.61 to 0.69 for rennet coagulation time and 0.46 to 0.52 for curd firmness) were lower than those obtained in the present study for traits with similar average $R^{2}$ values $\left(0.60\right.$ to 0.76 for $C Y_{\text {WATER }}, 0.27$ to 0.46 for $\mathrm{REC}_{\mathrm{FAT}}$, and 0.65 to 0.75 for energy recovery; Table 1), and much lower for traits with higher average $\mathrm{R}^{2}$ values (Table 1 ). Notably, the validation set used in the present study was totally external with respect to the calibration sets (i.e., containing data from cows of different herds and sampled on different dates), whereas the previous study assessed 2 sets of data that represented different cows but were taken from the same herds and on the same sampling dates. In seeking to use FTIR calibrations to predict milk calcium and phosphorus contents (which were characterized by the highest $R^{2}$ values in our cross-validation, at 0.80 and 0.79 , respectively), Soyeurt et al. (2009) compared results of cross-validation with those obtained with a validation group of the same origin. The $\mathrm{R}^{2}$ values of the validation group were higher than those of the crossvalidation in both cases ( 0.97 and 0.88 , respectively). However, both sets had relatively small sample sizes (57 and 30, respectively), the variability of the mineral contents was much higher in the validation group, the distribution of the calcium content in the validation group was far from normal, and the authors did not report the standard errors of the predictions. In studying the use of FTIR calibrations to estimate the FA profiles of milk, Rutten et al. (2009) did not carry out a cross- 
Table 4. Posterior median and the lower and upper bounds of the $95 \%$ highest posterior density region (HPD95) for additive genetic and phenotypic correlations between measures of percentage model cheese yield (CY; weight of fresh curd, curd solids, and curd water as percentage of weight of milk processed) and daily production (dCY; curd, curd solids, and curd water produced per cow) and their predictions by mid-infrared spectroscopy (FTIR)

\begin{tabular}{|c|c|c|c|c|c|}
\hline \multirow[b]{2}{*}{ Item } & \multirow[b]{2}{*}{ Subset $^{1}$} & \multicolumn{2}{|c|}{ Genetic correlation } & \multicolumn{2}{|c|}{ Phenotypic correlation } \\
\hline & & $\mathrm{r}_{\mathrm{A}}$ & HPD95 & $\mathrm{r}_{\mathrm{P}}$ & HPD95 \\
\hline \multirow[t]{4}{*}{$\mathrm{CY}_{\mathrm{CURD}}, \%$} & $\mathrm{~B}+\mathrm{C}$ & 0.846 & $0.58 ; 0.96$ & 0.706 & $0.63 ; 0.76$ \\
\hline & $\mathrm{A}+\mathrm{C}$ & 0.905 & $0.67 ; 0.98$ & 0.663 & $0.57 ; 0.73$ \\
\hline & $\mathrm{A}+\mathrm{B}$ & 0.868 & $0.64 ; 0.97$ & 0.634 & $0.52 ; 0.71$ \\
\hline & $\mathrm{A}+\mathrm{B}+\mathrm{C}$ & 0.972 & $0.87 ; 0.99$ & 0.881 & $0.87 ; 0.90$ \\
\hline \multirow[t]{4}{*}{$\mathrm{CY}_{\text {SOLIDS }}, \%$} & $\mathrm{~B}+\mathrm{C}$ & 0.957 & $0.80 ; 0.99$ & 0.748 & $0.69 ; 0.79$ \\
\hline & $\mathrm{A}+\mathrm{C}$ & 0.950 & $0.71 ; 0.99$ & 0.822 & $0.78 ; 0.85$ \\
\hline & $\mathrm{A}+\mathrm{B}$ & 0.968 & $0.82 ; 0.99$ & 0.830 & $0.80 ; 0.85$ \\
\hline & $\mathrm{A}+\mathrm{B}+\mathrm{C}$ & 0.983 & $0.93 ; 0.99$ & 0.962 & $0.95 ; 0.97$ \\
\hline \multirow[t]{4}{*}{$\mathrm{CY}_{\text {WATER }}, \%$} & $\mathrm{~B}+\mathrm{C}$ & 0.522 & $-0.15 ; 0.98$ & 0.495 & $0.39 ; 0.58$ \\
\hline & $\mathrm{A}+\mathrm{C}$ & 0.727 & $0.16 ; 0.97$ & 0.459 & $0.32 ; 0.56$ \\
\hline & $\mathrm{A}+\mathrm{B}$ & 0.698 & $0.01 ; 0.97$ & 0.486 & $0.35 ; 0.59$ \\
\hline & $\mathrm{A}+\mathrm{B}+\mathrm{C}$ & 0.761 & $0.42 ; 0.94$ & 0.772 & $0.74 ; 0.81$ \\
\hline \multirow[t]{4}{*}{$\mathrm{dCY}_{\mathrm{CURD}}, \mathrm{kg} \times \mathrm{d}^{-1}$} & $\mathrm{~B}+\mathrm{C}$ & 0.986 & $0.89 ; 0.99$ & 0.956 & $0.94 ; 0.96$ \\
\hline & $\mathrm{A}+\mathrm{C}$ & 0.961 & $0.75 ; 0.99$ & 0.951 & $0.93 ; 0.97$ \\
\hline & $A+B$ & 0.987 & $0.93 ; 0.99$ & 0.960 & $0.89 ; 0.94$ \\
\hline & $\mathrm{A}+\mathrm{B}+\mathrm{C}$ & 0.988 & $0.92 ; 0.99$ & 0.983 & $0.98 ; 0.99$ \\
\hline \multirow{4}{*}{$\mathrm{dCY}_{\text {SOLIDS }}, \mathrm{kg} \times \mathrm{d}^{-1}$} & $\mathrm{~B}+\mathrm{C}$ & 0.984 & $0.87 ; 0.99$ & 0.943 & $0.92 ; 0.95$ \\
\hline & $\mathrm{A}+\mathrm{C}$ & 0.987 & $0.84 ; 0.99$ & 0.966 & $0.95 ; 0.97$ \\
\hline & $A+B$ & 0.993 & $0.94 ; 0.99$ & 0.973 & $0.96 ; 0.98$ \\
\hline & $\mathrm{A}+\mathrm{B}+\mathrm{C}$ & 0.996 & $0.98 ; 0.99$ & 0.995 & $0.96 ; 0.99$ \\
\hline \multirow{4}{*}{$\mathrm{dCY}_{\text {WATER, }} \mathrm{kg} \times \mathrm{d}^{-1}$} & $\mathrm{~B}+\mathrm{C}$ & 0.972 & $0.78 ; 0.98$ & 0.872 & $0.83 ; 0.90$ \\
\hline & $\mathrm{A}+\mathrm{C}$ & 0.887 & $0.55 ; 0.99$ & 0.871 & $0.82 ; 0.91$ \\
\hline & $\mathrm{A}+\mathrm{B}$ & 0.952 & $0.74 ; 0.99$ & 0.787 & $0.70 ; 0.84$ \\
\hline & $\mathrm{A}+\mathrm{B}+\mathrm{C}$ & 0.924 & $0.71 ; 0.99$ & 0.950 & $0.93 ; 0.96$ \\
\hline
\end{tabular}

Table 5. Posterior median and the lower and upper bounds of the $95 \%$ highest posterior density region (HPD95) for additive genetic and phenotypic correlations between measures of milk nutrient recovery in model cheeses (REC; protein, fat, solids, and energy of the curd as percentage of the protein, fat, solids, and energy of the milk processed) and their predictions by mid-infrared spectroscopy (FTIR)

\begin{tabular}{|c|c|c|c|c|c|}
\hline \multirow[b]{2}{*}{ Item } & \multirow[b]{2}{*}{ Subset $^{1}$} & \multicolumn{2}{|c|}{ Genetic correlation } & \multicolumn{2}{|c|}{ Phenotypic correlation } \\
\hline & & $\mathrm{r}_{\mathrm{A}}$ & HPD95 & $\mathrm{r}_{\mathrm{P}}$ & HPD95 \\
\hline \multirow[t]{4}{*}{ REC $_{\text {PROTEIN, }} \%$} & $\mathrm{~B}+\mathrm{C}$ & 0.901 & $0.63 ; 0.99$ & 0.587 & $0.50 ; 0.65$ \\
\hline & $\mathrm{A}+\mathrm{C}$ & 0.815 & $0.14 ; 0.98$ & 0.646 & $0.57 ; 0.70$ \\
\hline & $\mathrm{A}+\mathrm{B}$ & 0.807 & $0.39 ; 0.97$ & 0.560 & $0.47 ; 0.63$ \\
\hline & $\mathrm{A}+\mathrm{B}+\mathrm{C}$ & 0.881 & $0.67 ; 0.96$ & 0.863 & $0.84 ; 0.87$ \\
\hline \multirow{4}{*}{$\mathrm{REC}_{\mathrm{FAT},} \%$} & $\mathrm{~B}+\mathrm{C}$ & 0.894 & $0.57 ; 0.99$ & 0.383 & $0.27 ; 0.48$ \\
\hline & $\mathrm{A}+\mathrm{C}$ & 0.791 & $0.15 ; 0.98$ & 0.402 & $0.29 ; 0.49$ \\
\hline & $\mathrm{A}+\mathrm{B}$ & n.e. ${ }^{2}$ & n.e. & n.e. & n.e. \\
\hline & $\mathrm{A}+\mathrm{B}+\mathrm{C}$ & 0.794 & $0.49 ; 0.95$ & 0.632 & $0.58 ; 0.68$ \\
\hline \multirow[t]{4}{*}{ REC $_{\text {SOLIDS, }} \%$} & $\mathrm{~B}+\mathrm{C}$ & 0.928 & $0.71 ; 0.99$ & 0.629 & $0.55 ; 0.69$ \\
\hline & $\mathrm{A}+\mathrm{C}$ & 0.832 & $0.57 ; 0.98$ & 0.592 & $0.50 ; 0.66$ \\
\hline & $\mathrm{A}+\mathrm{B}$ & 0.981 & $0.86 ; 0.99$ & 0.603 & $0.51 ; 0.67$ \\
\hline & $\mathrm{A}+\mathrm{B}+\mathrm{C}$ & 0.982 & $0.93 ; 0.99$ & 0.891 & $0.88 ; 0.91$ \\
\hline \multirow{4}{*}{$\mathrm{REC}_{\text {ENERGY }}, \%$} & $\mathrm{~B}+\mathrm{C}$ & 0.932 & $0.74 ; 0.99$ & 0.719 & $0.66 ; 0.76$ \\
\hline & $\mathrm{A}+\mathrm{C}$ & 0.912 & $0.59 ; 0.99$ & 0.722 & $0.66 ; 0.77$ \\
\hline & $A+B$ & 0.932 & $0.73 ; 0.99$ & 0.744 & $0.69 ; 0.78$ \\
\hline & $\mathrm{A}+\mathrm{B}+\mathrm{C}$ & 0.963 & $0.87 ; 0.99$ & 0.905 & $0.89 ; 0.92$ \\
\hline
\end{tabular}

${ }^{1} \mathrm{~B}+\mathrm{C}=$ testing subset for the training subset $\mathrm{A} ; \mathrm{A}+\mathrm{C}=$ testing subset for the training subset $\mathrm{B} ; \mathrm{A}+\mathrm{B}$ $=$ testing subset for the training subset $\mathrm{C} ; \mathrm{A}+\mathrm{B}+\mathrm{C}=$ entire dataset used both for training and testing (internal cross-validation).

${ }^{2}$ n.e. $=$ not estimable. 
validation, but rather randomly divided their data set into 2 subsets and used one for calibration and the other for validation. Moreover, they performed their calibration-validation procedures separately on winter- or summer-collected samples. The authors found that the $\mathrm{R}^{2}$ values for their validation were always much lower in the winter or summer calibrations compared with the overall calibration. They also found a large variability of $\mathrm{R}^{2}$ when they used the validated calibration of one season to predict the fat composition of samples collected in the other season. Unfortunately, the authors did not report the standard errors of their predictions. More recently, the same authors (Rutten et al., 2011) used a similar procedure to predict the detailed milk protein composition and found that the validation $\mathrm{R}^{2}$ values (obtained from a separate randomly obtained subset) were generally low. In an international study on predicting the FA content of milk, Soyeurt et al. (2011) divided their calibration and validation sets based on the variability of their FTIR spectra; the most variable samples were used for calibrations, whereas the remainder were used for validation. They found that the $\mathrm{R}^{2}$ values obtained from their validation were often lower than those of their cross-validation, with larger differences seen for those with smaller values. Moreover, the $\mathrm{R}^{2}$ values were much lower for their validation of the content of individual FA expressed as a percent of milk fat, calculated on the basis of their predicted content in milk. Soyeurt et al. (2012) used external validation to test the ability of FTIR spectroscopy to predict the milk content of lactoferrin and found that the $\mathrm{R}^{2}$ values of their cross-validations varied between 0.74 and 0.69 according to the mathematical treatment of the FTIR spectra, whereas the $\mathrm{R}^{2}$ values of their external validations varied much more, from 0.60 to 0.27 . The authors did not include the standard error of their predictions. Recently, Maurice-Van Eijndhoven et al. (2013) tested the ability of FTIR calibrations to predict various FA contents in milk samples obtained from different breeds, countries, and laboratories by performing a real external calibration on cows of 4 breeds. The authors found that the validation $\mathrm{R}^{2}$ values were always lower than calibration $R^{2}$ values, especially for those $<0.90$ (the decrease varied from 0.01 to 0.47 ). Moreover, the standard errors of the predictions were always higher than those of their cross-validation (from 20 to $300 \%$, depending on the FA).

Collectively, these previous studies seem to suggest that cross-validation can be used to initially evaluate calibration equations when the number of reference samples is low, but cross-validation generally overestimates the prediction ability of FTIR calibrations. Moreover, the use of $\mathrm{R}^{2}$ values for cross-validation can contribute to a further overestimation of the predictive ability when the calibrations are carried out on data sets that are more variable than the samples used for predictions.

\section{Genetic Parameters of FTIR-Predicted CY and REC}

The genetic bases of the milk traits predicted by FTIR spectra have been demonstrated by studies showing that the absorbances of milk samples at individual wavelengths (Bittante and Cecchinato, 2013) or the absorbances of their principal components (Soyeurt et al., 2010) are often heritable. In particular, Bittante and Cecchinato (2013) showed an appreciable heritability for the absorbance of milk at several wavelengths associated with the chemical bonds that characterize many milk components. Several authors have estimated the genetic parameters of milk traits predicted through FTIR calibrations and compared their results with estimates previously reported for the measured traits using different populations, conditions, and methodologies. The FA content has been widely studied in milk (Soyeurt et al., 2007b; Arnould et al., 2010; Bastin et al., 2011) and beef (Cecchinato et al., 2012). Also, the genetic parameters of lactoferrin have been studied (Soyeurt et al., 2007a; Arnould et al., 2009). Our increasing knowledge of the genetic parameters of predicted traits allows us to consider using FTIR-based predictions as indicator traits for the genetic improvement of populations. As a first step toward this objective, we must compare the genetic parameters of the predicted and measured traits.

\section{Comparison Between the Genetic Parameters of FTIR-Predicted and Measured CY and REC}

In the present study, our calibrations based on the whole data set showed that, for traits related to $\mathrm{CY}$ and REC, the intraherd heritabilities of the predicted traits were similar to or slightly higher than those of the corresponding measured traits. The exceptions to this were the traits with the lowest calibration $\mathrm{R}^{2}$ values, $\mathrm{CY}_{\mathrm{WATER}}$ and $\mathrm{REC}_{\mathrm{FAT}}$, for which the intraherd heritabilities of the FTIR-predicted traits were much higher than those of the corresponding measured traits.

Very few previous studies have compared the genetic parameters of infrared-predicted and measured traits. Similar to the present study, Cecchinato et al. (2009) reported on the use of FTIR calibration to predict the rennet-coagulation time (RCT) and curd firmness $\left(\mathbf{a}_{\mathbf{3 0}}\right)$ of bovine milk. The obtained heritability estimates were slightly higher for the predicted RCT compared with the measured trait, and much higher in the case of $\mathrm{a}_{30}$. Consistent with our present findings, the difference was greater for the trait with the lower calibration $\mathrm{R}^{2}$. 
In a previous study, the genetic and residual variance components were both decreased by FTIR prediction; the decrease was greater for the residual variance, especially in the case of $\mathrm{a}_{30}$, explaining the observed differences in heritability. In the present study, the differences in the genetic variance between the predicted and measured traits ranged from 8 (CY $\left.\mathrm{CY}_{\text {SOLIDS }}\right)$ to $-23 \%$ $\left(\mathrm{REC}_{\mathrm{FAT}}\right)$, whereas the differences in the residual variance ranged from $-7\left(\mathrm{CY}_{\mathrm{SOLIDS}}\right)$ to $-59 \%\left(\mathrm{REC}_{\mathrm{FAT}}\right)$. In comparing the genetic parameters of 8 measured and NIR-predicted technological traits of beef, Cecchinato et al. (2011) found a close negative relationship between the $\mathrm{R}^{2}$ values of their calibrations and the losses of both genetic and residual variance components. Furthermore, Rutten et al. (2011) found that the intraherd heritabilities of milk protein fractions characterized by moderate calibration $R^{2}$ values (0.57-0.59) were greater than the heritabilities of the traits with higher $\mathrm{R}^{2}$ values (0.23-0.44). Different from the present and previous studies, comparing the heritabilities of the FTIRpredicted protein content of bovine milk (Rutten et al., 2011) with the corresponding measured traits obtained from the same population (Schopen et al., 2009) shows that the heritabilities of the predicted values are always lower than those of the measured ones. Unfortunately, the variance components of the predicted values were not reported in the previous studies.

In the present work, FTIR-based prediction reduced the variance components related to herd test date more than the other components (e.g., by $-9 \%$ for $\mathrm{CY}_{\text {SOLIDS }}$ to $-49 \%$ for $\mathrm{REC}_{\mathrm{FAT}}$ ), such that the increases in the across-herd heritabilities of the predicted values were slightly higher than those of the intraherd heritabilities. In a previous study on milk coagulation traits, the herd variance component was not decreased by FTIR prediction in the case of RCT, but it was almost halved in the case of $\mathrm{a}_{30}$ (Cecchinato et al., 2009). The herds were only sampled once in the present study, so we do not know if the decrease reflected a sampling date component or a herd-structure herd component.

Clearly, when the genetic and residual variances are smaller, the observation of similar or even higher heritability values does not guarantee that the FTIRpredicted values will yield the same genetic improvements that may be achieved using direct measurements of the trait. Thus, it is essential that we increase our knowledge of the genetic correlations between predicted and measured traits.

Although the phenotypic correlations between the predicted and measured CY and nutrient REC traits were in line with the FTIR-based external validation coefficients of determination, the genetic correlations were similar to or higher than the phenotypic ones; they were very high in general $(>0.88)$, with the exceptions of $\mathrm{CY}_{\text {WATER }}$ (0.76) and $\mathrm{REC}_{\mathrm{FAT}}$ (0.79). Similar results (i.e., higher genetic correlations than phenotypic correlations between FTIR-predicted and measured traits) have been found for other traits. Cecchinato et al. (2009) obtained genetic correlations $>0.90$ between the FTIR-predicted and observed RCT, and correlations of 0.71 to 0.87 for $\mathrm{a}_{30}$. Rutten et al. (2011) found genetic correlations $>0.60$ for all studied milk protein fractions. Cecchinato et al. (2011) found that the NIR-predicted technological traits of beef showed high genetic correlations $(>0.70)$ for all traits, with a heritability $>0.10$ for measured values. Thus, it appears that FTIR-based calibration could be a valuable tool for informing the genetic improvement of economically important traits, especially in cases where population-level recording is complex and expensive.

\section{Comparison Between the Genetic Parameters of FTIR-Predicted Traits Obtained by Internal Cross-Validation or External Validation}

To the best of our knowledge, ours is the first study to compare the genetic parameters of measured traits with those predicted by FTIR-based calibrations obtained from a large data set using cross-validation on the same data set or on much smaller data sets, followed by an external validation. The calibration was performed on one-third of the reference data and repeated 3 times, as seen in Table 1 . We obtained 1 - VR coefficients comparable with the calibrations obtained using the whole data set (averaging $4 \%$ for $\mathrm{REC}_{\text {WATER }}$ to $-6 \%$ for $\mathrm{REC}_{\mathrm{FAT}}$ ), but the external validation coefficients of determination were much smaller and variable than those obtained from the cross-validation. In fact, the average $R_{V}^{2}$ coefficient of the 3 external validations for each predicted trait was $74 \%$ of the average value of the corresponding 1 - VR coefficient obtained from cross-validation in the case of $\mathrm{CY}_{\text {SOLIDS, }}$ and dropped to only $37 \%$ in the case of $\mathrm{REC}_{\mathrm{FAT}}$.

The heritability coefficients did not differ greatly between the predicted and measured traits or between those obtained from the testing (two-thirds of the whole data set used for external validation) or full (crossvalidation) data sets. The only evident differences were noted for $\mathrm{CY}_{\mathrm{WATER}}$ and $\mathrm{REC}_{\mathrm{FAT}}$, which also had the lowest calibration 1 - VR values. In both cases, the average heritability values obtained from the external validation data sets were lower than those obtained from the cross-validation data set. With respect to the variance components, the average genetic variances from the testing data sets were generally smaller than the corresponding estimates from the whole data set $(-16$ to $-42 \%)$. A similar pattern was seen for the residual variances ( -3 to $-28 \%$ ), with the exception of 
$\operatorname{REC}_{\mathrm{FAT}}(-57 \%)$. In the case of the HTD variance components, the variability was much higher, with higher values often estimated from the testing data set than the cross-validation data sets.

Cecchinato et al. (2009) did not carry out a true external validation, as their validation subsets were sampled at random from the whole data set and thus included samples from the same herd and sampling dates found in the calibration subsets. However, theirs was the only previous work to report the genetic parameters of different data sets (4 of them) created using calibrations obtained from separated data sets. Similar to our findings, those authors found that the genetic parameters of the FTIR-predicted traits were more variable than those estimated from measured traits, and the variability was greater for the trait with the lower calibration 1 - VR (i.e., $\mathrm{a}_{30}$ ) than for that with the higher 1 - VR (i.e., RCT).

Regarding the genetic correlations between the FTIRpredicted and measured traits, the decreased correlations found for the reduced validation data sets versus the whole cross-validation data set were $<10 \%$ (Tables 4 and 5), with the exceptions of $\mathrm{CY}_{\text {WATER }}(-15 \%)$ and $\mathrm{REC}_{\mathrm{FAT}}$ (which failed to yield estimable values in 1 of the 3 validation data sets). In a previous study on milk coagulation properties (Cecchinato et al., 2009), the variability of the genetic correlation estimates was greater for the trait with the lowest $1-\mathrm{VR}$ values $\left(\mathrm{a}_{30}\right.$ of 0.71 to 0.87 ) than for the that with the highest $1-$ VR values (RCT of 0.91 to 0.96 ). In a previous study on the technological traits of beef (Cecchinato et al. 2011), the genetic correlations between the predicted and measured traits were not strictly linked to the other genetic or phenotypic parameters of the traits, but rather seemed to depend more on the coefficient of determination for the calibration than on the heritability coefficients.

\section{CONCLUSIONS}

The present study investigated calibrations based on the FTIR spectra of fresh unprocessed milk samples and examined the their potential use for the genetic improvement of 10 traits related to $\mathrm{CY}$, milk nutrient REC in curd or loss in whey, and daily cheese production per cow. The heritability estimates of the FTIR-predicted cheese traits ranged from moderately low (daily cheese production) to high (protein recovery in curd or loss in whey) values. The heritability values of the predicted cheese traits were very similar to those estimated from the corresponding measured traits, with the partial exceptions of the prediction for the percent of water retained in the curd and fat recovery. The genetic correlations between each predicted and measured trait were generally high, and they were higher than the corresponding phenotypic correlations. Our external validations showed that the use of internal validation tends to overestimate the predictive ability of FTIR calibrations. Even when the coefficient of determination for the validation was moderate, our genetic analyses showed high genetic correlations between the measured and predicted values. Collectively, these results show that the use of FTIR calibrations on samples collected for milk recording of dairy cows could allow the rapid and fairly inexpensive prediction of several traits related to CY and cheese-making efficiency in dairy cow populations. These predictions could therefore prove useful for the efficient selection of dairy populations. Future work is warranted to examine the economic importance of these traits and their improvement in dairy populations and to establish their optimal weights for use in selection indices.

\section{ACKNOWLEDGMENTS}

The authors thank the Autonomous Province of Trento (Italy) for funding the project; the potenziamento della rete di infrastrutture a supporto dell'innovazione biotecnologica (RISIB) Regional competitiveness and job creation (SMUPR project 4145) for granting access to the instruments of the Near-Infrared Spectroscopy (NIRS) Food Laboratory (University of Padova, Legnaro, Italy); and the Superbrown Consortium of Bolzano and Trento (Trento, Italy) for their sampling and recording activities.

\section{REFERENCES}

Ali, A. K. A., and G. E. Shook. 1980. An optimum transformation for somatic cell concentration in milk. J. Dairy Sci. 63:487-490.

Arnould, V. M.-R., H. Hammami, H. Soyeurt, and N. Gengler. 2010. Short communication: Genetic variation of saturated fatty acids in Holsteins in the Walloon region in Belgium. J. Dairy Sci. 93:4391-4397.

Arnould, V. M.-R., H. Soyeurt, N. Gengler, F. G. Colinet, M. V. Georges, C. Bertozzi, D. Portetelle, and R. Renaville. 2009. Genetic analysis of lactoferrin content in bovine milk. J. Dairy Sci. 92:2151-2158.

Barbano, D. M., and J. M. Lynch. 2006. Major advances in testing of dairy products: Milk component and dairy product attribute testing. J. Dairy Sci. 89:1189-1194.

Bastin, C., N. Gengler, and H. Soyeurt. 2011. Phenotypic and genetic variability of production traits and milk fatty acid contents across days in milk for Walloon Holstein first-parity cows. J. Dairy Sci. 94:4152-4163.

Bittante, G., and A. Cecchinato. 2013. Genetic analysis of the Fouriertransform infrared spectra of bovine milk with emphasis to individual wavelengths related to specific chemical bonds. J. Dairy Sci. 96:5991-6006.

Bittante, G., C. Cipolat-Gotet, and A. Cecchinato. 2013. Genetic parameters of different measures of cheese yield and milk nutrients recovery from an individual model cheese-manufacturing process. J. Dairy Sci. 96:7966-7979. 
Bittante, G., M. Penasa, and A. Cecchinato. 2012. Invited review: Genetics and modeling of milk coagulation properties. J. Dairy Sci. 95:6843-6870.

Brandt, M., A. Haeussermann, and E. Hartung. 2010. Invited review: Technical solutions for analysis of milk constituents and abnormal milk. J. Dairy Sci. 93:427-436.

Caraviello, D. Z., K. A. Weigel, and D. Gianola. 2004. Comparison between a Weibull proportional hazards model and a linear model for predicting the genetic merit of US Jersey sires for daughter longevity. J. Dairy Sci. 87:1469-1476.

Cecchinato, A., C. Cipolat-Gotet, J. Casellas, M. Penasa, A. Rossoni, and G. Bittante. 2013. Genetic analysis of rennet coagulation time, curd-firming rate, and curd firmness assessed over an extended testing period using mechanical and near-infrared instruments. J. Dairy Sci. 96:50-62.

Cecchinato, A., M. De Marchi, L. Gallo, G. Bittante, and P. Carnier 2009. Mid-infrared spectroscopy predictions as indicator traits in breeding programs for enhanced coagulation properties of milk. J. Dairy Sci. 92:5304-5313.

Cecchinato, A., M. De Marchi, M. Penasa, A. Albera, and G. Bittante. 2011. Near-infrared reflectance spectroscopy predictions as indicator traits in breeding programs for enhanced beef quality. J. Anim. Sci. 89:2687-2695.

Cecchinato, A., M. De Marchi, M. Penasa, J. Casellas, S. Schiavon, and G. Bittante. 2012. Genetic analysis of beef fatty acid composition predicted by near-infrared spectroscopy. J. Anim. Sci 90:429-438.

Cipolat-Gotet, C., A. Cecchinato, M. De Marchi, and G. Bittante. 2013. Factors affecting variation of different measures of cheese yield and milk nutrients recovery from an individual model cheesemanufacturing process. J. Dairy Sci. 96:7952-7965.

Cipolat-Gotet, C., A. Cecchinato, M. De Marchi, M. Penasa, and G. Bittante. 2012. Comparison between mechanical and near-infrared optical methods for assessing coagulation properties of bovine milk. J. Dairy Sci. 95:6806-6819.

Dagnachew, B. S., T. H. Meuwissen, and T. Adnøy. 2013. Genetic components of milk Fourier transform infrared spectra used to predict breeding values for milk composition and quality traits in dairy goats. J. Dairy Sci. 96:5933-5942

Dal Zotto, R., M. De Marchi, A. Cecchinato, M. Penasa, M. Cassandro, P. Carnier, L. Gallo, and G. Bittante. 2008. Reproducibility and repeatability of measures of milk coagulation properties and predictive ability of mid-infrared reflectance spectroscopy. J. Dairy Sci. 91:4103-4112.

Etzion, Y.. R. Linker, U. Cogan, and I. Shmulevich. 2004. Determination of protein concentration in raw milk by mid-infrared Fourier transform infrared/attenuated total reflectance spectroscopy. J. Dairy Sci. 87:2779-2788.

Ferragina, A., C. Cipolat-Gotet, A. Cecchinato, and G. Bittante. 2013 The use of Fourier-transform infrared spectroscopy to predict cheese yield and nutrient 14 recovery/whey loss traits from unprocessed bovine milk samples. J. Dairy Sci. 96:7980-7990.

Gelfand, A., and A. F. M. Smith. 1990. Sampling based approaches to calculating marginal densities. J. Am. Stat. Assoc. 85:398-409.

Gelman, A., and D. B. Rubin. 1992. Inference from iterative simulation using multiple sequences. Stat. Sci. 7:457-511.

Geweke, J. 1992. Evaluating the accuracy of sampling-based approaches to the calculation of posterior moments (with discussion). Pages 164-193 in Bayesian Statistics. J. O. Berger, J. M. Bernardo, A. P. Dawid, and A. F. M. Smith, ed. Oxford University Press, Oxford, UK.

Geyer, C. J. 1992. Practical Markov chain Monte Carlo. Stat. Sci. $7: 473-483$

Hewavitharana, A. K., and B. van Brakel. 1997. Fourier transform infrared spectrometric method for the rapid determination of casein in raw milk. Analyst (Lond.) 122:701-704.

International Committee for Animal Recording (ICAR). 2012. International agreement of recording practices - Guidelines approved by the general assembly held in Cork, Ireland on June 2012. ICAR, Rome, Italy.
Karoui, R., G. Downey, and C. Blecker. 2010. Mid-infrared spectroscopy coupled with chemometrics: A tool for the analysis of intact food systems and the exploration of their molecular structure-quality relationships-A review. Chem. Rev. 110:6144-6168.

Kaylegian, K. E., G. E. Houghton, J. M. Lynch, J. R. Fleming, and D. M. Barbano. 2006. Calibration of infrared milk analyzers: Modified milk versus producer milk. J. Dairy Sci. 89:2817-2832.

Kaylegian, K. E., J. M. Lynch, J. R. Fleming, and D. M. Barbano. 2009. Influence of fatty acid chain length and unsaturation on midinfrared milk analysis. J. Dairy Sci. 92:2485-2501.

Lynch, J. M., D. M. Barbano, M. Schweisthal, and J. R. Fleming. 2006. Precalibration evaluation procedures for mid-infrared milk analyzers. J. Dairy Sci. 89:2761-2774.

Mateo, M. J., D. J. O'Callaghan, C. D. Everard, M. Castillo, F. A. Payne, and C. P. O'Donnell. 2009. Validation of a curd-syneresis sensor over a range of milk composition and process parameters. J. Dairy Sci. 92:5386-5395.

Maurice-Van Eijndhoven, M. H. T., H. Soyeurt, F. Dehareng, and M. P. L. Calus. 2013. Validation of fatty acid predictions in milk using mid-infrared spectrometry across cattle breeds. Animal $7: 348-354$

Rutten, M. J. M., H. Bovenhuis, J. M. L. Heck, and J. A. M. van Arendonk. 2011. Predicting bovine milk protein composition based on Fourier transform infrared spectra. J. Dairy Sci. 94:5683-5690.

Rutten, M. J. M., H. Bovenhuis, K. A. Hettinga, H. J. F. van Valenberg, and J. A. M. van Arendonk. 2009. Predicting bovine milk fat composition using infrared spectroscopy based on milk samples collected in winter and summer. J. Dairy Sci. 92:6202-6209.

Rutten, M. J. M., H. Bovenhuis, and J. A. M. van Arendonk. 2010 The effect of the number of observations used for Fourier transform infrared model calibration for bovine milk fat composition on the estimated genetic parameters of the predicted data. J. Dairy Sci. 93:4872-4882.

Schopen, G. C. B., J. M. L. Heck, H. Bovenhuis, M. H. P. W. Visker, H. J. F. Valenberg, and J. A. M. van Arendonk. 2009. Genetic parameters for major milk proteins in Dutch Holstein-Friesians. J. Dairy Sci. 92:1182-1191.

Sorensen, D., and D. Gianola. 2002. Likelihood, Bayesian, and MCMC Methods in Quantitative Genetics. Springer-Verlag, New York, NY.

Soyeurt, H., C. Bastin, F. G. Colinet, V. M. R. Arnould, D. P. Berry, E. Wall, F. Dehareng, H. N. Nguyen, P. Dardenne, J. Schefers, J. Vandenplas, K. Weigel, M. Coffey, L. Theron, L. J. Detilleux, E. Reding, N. Gengler, and S. McParland. 2012. Mid-infrared prediction of lactoferrin content in bovine milk: Potential indicator of mastitis. Animal 6:1830-1838.

Soyeurt, H., D. Bruwier, J.-M. Romnee, N. Gengler, C. Bertozzi, D. Veselko, and P. Dardenne. 2009. Potential estimation of major mineral contents in cow milk using mid-infrared spectrometry. J. Dairy Sci. 92:2444-2454.

Soyeurt, H., F. G. Colinet, V. M.-R. Arnould, P. Dardenne, C. Bertozzi, R. Renaville, D. Portetelle, and N. Gengler. 2007a. Genetic variability of lactoferrin content estimated by mid-infrared spectrometry in bovine milk. J. Dairy Sci. 90:4443-4450.

Soyeurt, H., F. Dehareng, N. Gengler, S. McParland, E. Wall, D. P. Berry, and M. Coffey. 2011. Mid-infrared prediction of bovine milk fatty acids across multiple breeds, production systems, and countries. J. Dairy Sci. 94:1657-1667.

Soyeurt, H., A. Gillon, S. Vanderick, P. Mayeres, C. Bertozzi, and N. Gengler. 2007b. Estimation of heritability and genetic correlations for the major fatty acids in bovine milk. J. Dairy Sci. 90:4435-4442.

Soyeurt, H., I. Misztal, and N. Gengler. 2010. Genetic variability of milk components based on mid-infrared spectral data. J. Dairy Sci. 93:1722-1728.

Sturaro, E., E. Marchiori, G. Cocca, M. Penasa, M. Ramanzin, and G. Bittante. 2013. Dairy systems in mountainous areas: Farm animal biodiversity, milk production and destination, and land use. Livest. Sci. 158:157-168. 